\title{
BMJ
}

\section{Prepregnancy cardiovascular risk factors as predictors of pre-eclampsia: population based cohort study}

\author{
Elisabeth Balstad Magnussen, research fellow, ${ }^{1}$ Lars Johan Vatten, professor, ${ }^{2}$ Tom Ivar Lund-Nilsen, \\ associate professor, ${ }^{2}$ Kjell Åsmund Salvesen, professor, ${ }^{3}$ George Davey Smith, professor, ${ }^{4}$ \\ Pål Richard Romundstad, associate professor ${ }^{2}$
}

\begin{abstract}
${ }^{1}$ Department of Public Health,
Faculty of Medicine, Norwegian

University of Science and

Technology, N-7489 Trondheim,

Norway, and Trondheim University

Hospital St Olav, Department of

Obstetrics, Trondheim

${ }^{2}$ Department of Public Health,

Faculty of Medicine, Norwegian

University of Science and

Technology

${ }^{3}$ Trondheim University Hospital

St Olav, Department of Obstetrics,

Trondheim, and Women and Child

Health, Norwegian University of

Science and Technology,

Trondheim

${ }^{4}$ Department of Social Medicine,

University of Bristol

Correspondence to: EB Magnussen

elisabeth.b.magnussen@ntnu.no
\end{abstract}

doi:10.1136/bmj.39366.416817.BE

\section{ABSTRACT}

Objective To examine the effect of cardiovascular risk factors before pregnancy on risk of pre-eclampsia.

Design Population based prospective study.

Setting Linkage between a Norwegian population based

study (Nord-Trøndelag health study, HUNT-2) and

Norway's medical birth registry.

Participants 3494 women who gave birth after participating in the Nord-Trøndelag health study at baseline; of whom 133 (3.8\%) delivered after a preeclamptic pregnancy.

Main outcome measure Odds ratio of developing preeclampsia.

Results After adjustment for smoking; previous preeclampsia; parity; maternal age, education, and socioeconomic position; and duration between baseline measurements and delivery, positive associations were found between prepregnancy serum levels of triglycerides, cholesterol, low density lipoprotein cholesterol, non-high density lipoprotein cholesterol, and blood pressure and risk of pre-eclampsia. The odds ratio of developing preeclampsia for women with baseline systolic blood pressures greater than $130 \mathrm{~mm} \mathrm{Hg}$ (highest fifth) was 7.3 (95\% confidence interval 3.1 to 17.2 ) compared with women with systolic blood pressures less than $111 \mathrm{~mm} \mathrm{Hg}$ (lowest fifth). Similar results were found for nulliparous and parous women. Women who used oral contraceptives at baseline had half the risk of pre-eclampsia compared with never or former users (0.5, 0.3 to 0.9$)$.

Conclusion Women with cardiovascular risk factors may be predisposed to pre-eclampsia.

\section{INTRODUCTION}

Pre-eclampsia occurs in about 3-5\% of pregnancies and is an important cause of fetal and maternal morbidity and mortality worldwide. Studies have shown that women with a history of pre-eclampsia are at increased risk of cardiovascular diseases, ${ }^{1-3}$ suggesting that preeclampsia and cardiovascular diseases may share common causes or mechanisms. ${ }^{45}$ In healthy pregnancies adaptive changes take place in women's physiology to meet demands of the rapidly developing fetus. Gestational hyperlipidaemia, a degree of insulin resistance, and up-regulation of inflammatory markers are among changes that occur. ${ }^{4-7}$ In pregnancies complicated by pre-eclampsia these normally adaptive metabolic responses are further exaggerated. ${ }^{4-7}$

Several studies have shown that women with preeclampsia have unfavourable cardiovascular risk profiles in pregnancy, associated with levels of serum lipids, body mass, and blood pressure. ${ }^{4578}$ It remains uncertain if these characteristics reflect primary causes of preeclampsia or if they are secondary markers of the disease process. It is also uncertain whether the increased risk of cardiovascular disease subsequent to pre-eclampsia is due to exposures during that pregnancy or due to underlying biological traits of the mother.

By studying risk factors before pregnancy, these issues could be tackled. Few studies have investigated potentially modifiable cardiovascular risk factors before conception in relation to risk of pre-eclampsia. We prospectively examined whether cardiovascular risk factors before pregnancy can predict pre-eclampsia.

\section{METHODS}

The present study is based on a linkage between a Norwegian population based health study and Norway's medical birth registry. We invited all residents of Nord Trøndelag County in Norway aged 20 years or more to participate in the Nord-Trøndelag health study (HUNT-2) between 1995 and 1997. ${ }^{9}$ Overall, 66140 of 94194 eligible adults $(71.2 \%)$ participated. The NordTrøndelag health study includes standardised measurements of height, weight, waist circumference, blood pressure, and non-fasting measurements of serum lipids and glucose levels. A comprehensive questionnaire contained queries on medical and lifestyle factors, including history of diabetes and cardiovascular disease, smoking, and educational attainment. We also investigated the influence of a family history of cardiovascular diseases and diabetes on risk of preeclampsia. Social position was evaluated on the basis of self reported employment status and whether the women received social security benefits. To obtain information on all births that had occurred from 1995 to March 2005 we linked all participating women to Norway's medical birth registry. We identified 4251 women giving birth to a singleton with a gestational age of more than 22 weeks or birth weight above $500 \mathrm{~g}$, at least nine months after the baseline study. 
We excluded 734 women who were pregnant during the survey and 23 women who had not attended the clinical examination in the Nord-Trøndelag health study (only participated with questionnaire data). This left 3494 women for the analyses and, among these, $133(3.8 \%)$ had a pregnancy complicated by pre-eclampsia.

All deliveries in Norway are recorded in the medical birth registry..$^{10}$ The registration is mandatory and based on standardised forms completed by midwives at the delivery units. The registry contains information on the mother's health before and during pregnancy, as well as on complications in pregnancy and perinatal data of the fetus. Pre-eclampsia is routinely entered on the form as a specified diagnosis. The diagnostic criteria of pre-eclampsia in Norway follows international classification systems, and the diagnosis is defined as a sustained increase in blood pressure to at least 140/90 mm $\mathrm{Hg}$ after mid-gestation combined with proteinuria of at least + or more on a semiquantitative dipstick. Hypertension and proteinuria should be apparent at two different occasions at least 4-6 hours apart. ${ }^{11}$

\section{Prepregnancy measurements}

Specially trained nurses or technicians measured blood pressure using an automatic oscillometric method (Dina map 845 XT; Criticon, Tampa, FL) after participants had rested in the sitting position for a minimum of two minutes. Blood pressure was measured three times at intervals of one minute, and we used the mean of the second and third reading in this study.

Blood sampling was done in the non-fasting state, and we analysed serum concentrations of total cholesterol, high density lipoprotein cholesterol, triglycerides, and glucose subsequent to sampling. ${ }^{9}$ A Hitachi 911 Auto analyzer (Mito, Japan) was used to analyse serum lipid levels, with reagents from Boehringer Mannheim (Mannheim, Germany). We measured levels of total cholesterol and high density lipoprotein cholesterol after precipitation with phosphor tungsten and magnesium ions, and triglyceride levels with an enzymatic calorimetric method. Glucose was measured using an enzymatic hexokinase method. Day to day coefficients of variation were $1.3 \%-1.9 \%$ for total cholesterol, $2.4 \%$ for high density lipoprotein cholesterol, $0.7 \%-1.3 \%$ for triglycerides, and 1.3\%-2.0\% for glucose. We used the Friedewald formula to calculate cholesterol levels - that is, low density lipoprotein cholesterol=total serum cholesterol-high density lipoprotein cholesterol-one fifth of the triglyceride concentration. ${ }^{12}$ We calculated low density lipoprotein cholesterol levels in participants only with triglyceride concentrations less than $4.5 \mathrm{mmol} / \mathrm{l}$. We also calculated non-high density lipoprotein cholesterol levels as the difference between levels of total serum cholesterol and high density lipoprotein cholesterol. Non-high density lipoprotein cholesterol incorporates low density lipoprotein cholesterol in addition to cholesterol content of other atherogenic lipoproteins. ${ }^{13}$ Trained study staff recorded height and weight with participants wearing light clothes and no shoes; height was measured to the nearest $1.0 \mathrm{~cm}$ and weight to the nearest $0.5 \mathrm{~kg} .{ }^{9}$ Body mass index was calculated as weight/height ${ }^{2}$. Waist circumference was measured with the participant standing upright, using a steel band to measure horizontally at the height of the umbilicus, and rounded to the nearest $1.0 \mathrm{~cm} .^{9}$

\section{Statistical analysis}

We used logistic regression analysis to estimate crude and adjusted associations of cardiovascular risk factors

Table 1 | Characteristics of women with pre-eclampsia or no pre-eclampsia before and during pregnancy. Values are numbers (percentages) unless stated otherwise

\begin{tabular}{|c|c|c|}
\hline Characteristics & $\begin{array}{l}\text { Pre-eclampsia group } \\
\qquad(\mathrm{n}=133)\end{array}$ & $\begin{array}{l}\text { No pre-eclampsia group } \\
\qquad(\mathrm{n}=3361)\end{array}$ \\
\hline Mean (SD) age at baseline (years) & $25.4(4.5)$ & $26.7(4.5)$ \\
\hline Mean (SD) maternal age at delivery (years) & $29.3(4.4)$ & $30.2(4.4)$ \\
\hline Prepregnancy diabetes* & $2(2.6)$ & $9(0.3)$ \\
\hline \multicolumn{3}{|l|}{ Parity: } \\
\hline 0 & $85(63.9)$ & $1403(41.7)$ \\
\hline 1 & $26(19.5)$ & $946(28.1)$ \\
\hline$\geq 2$ & $22(16.5)$ & $1012(30.1)$ \\
\hline$>37$ & $97(72.3)$ & $3188(94.9)$ \\
\hline Median (interquartile range) gestational age (days) & $272(27)$ & $281(15)$ \\
\hline Median (interquartile range) birth weight $(\mathrm{kg})$ & $3.3(1.0)$ & $3.6(0.7)$ \\
\hline Small for gestational age ( 10 centile) & $24(18.0)$ & $291(8.6)$ \\
\hline
\end{tabular}

*Nine women had type 1 diabetes and two had type 2 diabetes.

tHypertension defined as blood pressure above 140/90 ( $\mathrm{mm} \mathrm{Hg})$. One woman received antihypertensive treatment.

‡Percentage among those with a previous birth. 
with risk of pre-eclampsia. In the adjusted analyses we controlled for the interval from baseline measurements at the Nord-Trøndelag health study to the index birth, maternal age, parity, history of pre-eclampsia, smoking (never, former, or current), educational level, and whether the women received social security benefits. In the analyses of lipids we also adjusted for time since last meal. To avoid the influence of long term consequences from a previous pregnancy, we also stratified by parity to examine whether the associations differed between nulliparous and parous women. We separately studied associations with early onset preeclampsia by using pre-eclampsia with preterm delivery as a diagnostic indicator. The data were analysed using SPSS version 14.0 for Windows.

\section{RESULTS}

The mean age at baseline in the Nord-Trøndelag health study was 25.4 years for women who later developed pre-eclampsia and 26.7 years for women without preeclampsia (table 1). On average, time from baseline to delivery was four years in the pre-eclampsia group and 3 . 5 years in the non-pre-eclampsia group. Women with diabetes before pregnancy, chronic hypertension, or previous pre-eclampsia were over-represented in the pre-eclampsia group, and the proportion of nulliparous women was also higher in the pre-eclampsia group $(64 \%$ $v 42 \%$ ). Women with preterm delivery and women who delivered a small for gestational age infant were more likely to have a diagnosis of pre-eclampsia.

Women who were former and current smokers had a lower risk of pre-eclampsia compared with women who did not smoke (table 2), and women who received social security benefits seemed to be at higher risk than those who did not receive such benefits. Higher educational level was associated with reduced risk of pre-eclampsia. Women with more than 14 years of education had $70 \%$ (95\% confidence interval $20 \%$ to $90 \%$ ) lower risk of

$\overline{\text { Table } 2 \text { | Odds ratio for pre-eclampsia by smoking, socioeconomic status, use of oral contraceptives, and history of cardiovascular }}$ diseases and diabetes in first degree relatives

\begin{tabular}{|c|c|c|c|c|}
\hline \multirow[b]{2}{*}{ Variables } & \multirow{2}{*}{$\begin{array}{l}\text { Women with pre- } \\
\text { eclampsia/women without } \\
\text { pre-eclampsia* }\end{array}$} & \multicolumn{2}{|c|}{ Odds ratio $(95 \% \mathrm{Cl})$} & \multirow[b]{2}{*}{$P$ value } \\
\hline & & Crude estimate & Adjusted estimate $\dagger$ & \\
\hline \multicolumn{5}{|l|}{ Smoking } \\
\hline Never & $97 / 1995$ & 1.0 (reference) & 1.0 (reference) & \multirow[t]{3}{*}{0.03} \\
\hline Former & $11 / 426$ & $0.5(0.3$ to 1.0$)$ & $0.6(0.3$ to 1.3$)$ & \\
\hline Current & $25 / 930$ & $0.6(0.4$ to 0.9$)$ & $0.5(0.3$ to 0.9$)$ & \\
\hline \multicolumn{5}{|c|}{ Social security benefits $\ddagger$} \\
\hline No & $15 / 232$ & 1.0 (reference) & 1.0 (reference) & \multirow[t]{2}{*}{0.06} \\
\hline Yes & $115 / 3108$ & 1.7 (1.0 to 3.0$)$ & 1.6 (0.9 to 2.8$)$ & \\
\hline \multicolumn{5}{|c|}{ Education (years)§ } \\
\hline$<9$ & $9 / 204$ & 1.0 (reference) & 1.0 (reference) & \multirow[t]{4}{*}{0.02} \\
\hline $9-12$ & $33 / 907$ & $0.8(0.4$ to 1.7$)$ & 0.7 (0.3 to 1.5$)$ & \\
\hline $12-14$ & $78 / 1828$ & $1.0(0.5$ to 1.9$)$ & $0.6(0.3$ to 1.3$)$ & \\
\hline$>14$ & $8 / 388$ & $0.5(0.2$ to 1.2$)$ & 0.3 (0.1 to 0.8$)$ & \\
\hline \multicolumn{5}{|c|}{ Oral contraceptive useđ } \\
\hline Never & $21 / 319$ & 1.0 (reference) & 1.0 (reference) & \multirow[t]{3}{*}{0.04} \\
\hline Former & $57 / 1416$ & $0.6(0.4$ to 1.0$)$ & 1.1 (0.6 to 2.0$)$ & \\
\hline At baseline & $35 / 1117$ & $0.5(0.3$ to 0.8$)$ & $0.6(0.3$ to 1.0$)$ & \\
\hline \multicolumn{5}{|c|}{ Family history ${ }^{\star \star}$} \\
\hline \multicolumn{5}{|c|}{ Cerebrovascular stroke: } \\
\hline No & $113 / 2775$ & 1.0 (reference) & 1.0 (reference) & \multirow[t]{2}{*}{0.7} \\
\hline Yes & $4 / 131$ & $0.7(0.3$ to 2.0$)$ & 0.8 (0.3 to 2.3$)$ & \\
\hline \multicolumn{5}{|c|}{ Myocardial ischaemia: } \\
\hline No & $102 / 2634$ & 1.0 (reference) & 1.0 (reference) & \multirow[t]{2}{*}{0.07} \\
\hline Yes & $15 / 273$ & $1.3(0.5$ to 3.7$)$ & 1.7 (1.0 to 3.0$)$ & \\
\hline \multicolumn{5}{|c|}{ Hypertension: } \\
\hline No & $65 / 2040$ & 1.0 (reference) & 1.0 (reference) & \multirow[t]{2}{*}{0.001} \\
\hline Yes & $52 / 867$ & 1.9 (1.3 to 2.7$)$ & 2.0 (1.3 to 2.9$)$ & \\
\hline \multicolumn{5}{|l|}{ Diabetes: } \\
\hline No & $104 / 2733$ & 1.0 (reference) & 1.0 (reference) & \multirow[t]{2}{*}{0.04} \\
\hline Yes & $13 / 174$ & 2.0 (1.1 to 3.6) & 1.9 (1.0 to 3.5$)$ & \\
\hline
\end{tabular}

*Some variation in number of women without pre-eclampsia owing to missing data.

tAdjusted for maternal age at birth, duration between baseline study and index delivery, parity, previous pre-eclampsia, and smoking.

łInformation missing on three women with pre-eclampsia.

§Information missing on five women with pre-eclampsia.

TInformation missing on 20 women with pre-eclampsia.

**Information missing on 16 women with pre-eclampsia. 
Table 3 | Odds ratio for pre-eclampsia according to fifths of prepregnancy systolic and diastolic blood pressure, body mass index, waist circumference, and height

\begin{tabular}{|c|c|c|c|c|}
\hline \multirow[b]{2}{*}{ Variables (fifths) } & \multirow{2}{*}{$\begin{array}{l}\text { Women with pre-eclampsia/ } \\
\text { women without pre- } \\
\text { eclampsia* }\end{array}$} & \multicolumn{2}{|c|}{ Odds ratio $(95 \% \mathrm{Cl})$} & \multirow[b]{2}{*}{ P for trend } \\
\hline & & Crude estimate & Adjusted estimate $\dagger$ & \\
\hline \multicolumn{5}{|c|}{$\begin{array}{l}\text { Systolic blood pressure (mm } \\
\mathrm{Hg}):\end{array}$} \\
\hline «111 & $6 / 664$ & 1.0 (reference) & 1.0 (reference) & \multirow[t]{5}{*}{$<0.001$} \\
\hline $111-116$ & $13 / 672$ & 2.1 (0.8 to 5.7$)$ & 2.1 (0.8 to 5.5$)$ & \\
\hline $117-121$ & $27 / 611$ & $4.9(2.1$ to 11.9$)$ & $4.3(1.8$ to 10.6$)$ & \\
\hline $122-129$ & $32 / 739$ & 4.8 (1.9 to 11.5$)$ & 4.1 (1.7 to 9.9) & \\
\hline$\geq 130$ & $55 / 675$ & 9.0 (3.9 to 21.1) & 7.3 (3.1 to 17.2 ) & \\
\hline \multicolumn{5}{|c|}{$\begin{array}{l}\text { Diastolic blood pressure }(\mathrm{mm} \\
\mathrm{Hg}) \text { : }\end{array}$} \\
\hline$<64$ & $7 / 637$ & 1.0 (reference) & 1.0 (reference) & \multirow[t]{5}{*}{$<0.001$} \\
\hline $64-67$ & $12 / 587$ & $1.8(0.7$ to 4.7$)$ & $1.9(0.7$ to 4.9$)$ & \\
\hline $68-71$ & $30 / 663$ & 4.1 (1.8 to 9.4$)$ & 4.3 (1.9 to 9.9) & \\
\hline $72-77$ & $34 / 788$ & 3.9 (1.7 to 8.8$)$ & 3.7 (1.6 to 8.5$)$ & \\
\hline$\geq 78$ & $50 / 686$ & $6.6(3.0$ to14.7) & 6.5 (2.9 to14.6) & \\
\hline \multicolumn{5}{|l|}{ Body mass index: } \\
\hline$<21.23$ & $20 / 669$ & 1.0 (reference) & 1.0 (reference) & \multirow[t]{5}{*}{0.02} \\
\hline $21.23-22.80$ & $18 / 686$ & $0.9(0.5$ to 1.7$)$ & $0.9(0.5$ to 1.8$)$ & \\
\hline $22.81-24.53$ & $25 / 672$ & $1.2(0.7$ to 2.3$)$ & $1.3(0.7$ to 2.3$)$ & \\
\hline $24.54-27.07$ & $35 / 662$ & 1.8 (1.0 to 3.1$)$ & 1.9 (1.1 to3.4) & \\
\hline$\geq 27.08$ & $34 / 663$ & 1.7 (1.0 to 3.0$)$ & $1.9(1.1$ to .4$)$ & \\
\hline \multicolumn{5}{|c|}{ Waist circumference $(\mathrm{cm})$ : } \\
\hline$<67$ & $22 / 694$ & 1.0 (reference) & 1.0 (reference) & \multirow[t]{5}{*}{$<0.001$} \\
\hline $68-71$ & $25 / 693$ & 1.1 (0.6 to 2.0$)$ & $1.2(0.7$ to 2.2$)$ & \\
\hline $72-76$ & $24 / 743$ & $1.0(0.6$ to 1.8$)$ & $1.2(0.7$ to 2.2$)$ & \\
\hline $77-82$ & $26 / 571$ & $1.4(0.8$ to 2.6$)$ & $1.7(1.0$ to 3.1$)$ & \\
\hline$\geq 83$ & $36 / 654$ & $1.7(1.0$ to 3.0$)$ & 2.2 (1.2 to 3.8$)$ & \\
\hline \multicolumn{5}{|l|}{ Height $(\mathrm{cm})$ : } \\
\hline$\ll 162$ & $34 / 805$ & 1.0 (reference) & 1.0 (reference) & \multirow[t]{5}{*}{0.6} \\
\hline $163-165$ & $21 / 645$ & 0.8 (0.4 to 1.3$)$ & $0.8(0.5$ to 1.4$)$ & \\
\hline $166-168$ & $33 / 677$ & 1.1 (0.7 to 1.9$)$ & $1.2(0.7$ to 2.0$)$ & \\
\hline $169-171$ & $19 / 561$ & $0.8(0.5$ to 1.4$)$ & 0.9 (0.5 to 1.5$)$ & \\
\hline$\geq 172$ & $26 / 669$ & $0.9(0.5$ to 1.5$)$ & $0.9(0.6$ to 1.6$)$ & \\
\hline
\end{tabular}

*Some variation in number of women without pre-eclampsia owing to missing data.

†Adjusted for maternal age at birth, duration between baseline study and index delivery, education, parity, previous pre-eclampsia, receiving social security benefits, and smoking.

pre-eclampsia than women with less than 9 years' education. Women who used oral contraceptives at baseline had nearly half the risk of pre-eclampsia of never or previous users (adjusted odds ratio 0.6, 95\% confidence interval 0.3 to 1.0$)$, but duration of use was not associated with risk of pre-eclampsia (data not shown). Family history of cerebrovascular disease showed no association, but a family history of hypertension, ischaemic heart disease, or diabetes were each associated with a doubling in risk (table 2).

A strong and linear positive association was found between prepregnancy systolic and diastolic blood pressure and pre-eclampsia (table 3). After multivariable adjustment, the odds ratio for women with a baseline systolic blood pressure greater than $130 \mathrm{~mm} \mathrm{Hg}$ (highest fifth) was 7.3 (95\% confidence interval 3.1 to 17.2) compared with women with a systolic blood pressure less than $111 \mathrm{~mm} \mathrm{Hg}$ (lowest fifth). Similarly, the odds ratio for women with a diastolic blood pressure greater than $78 \mathrm{~mm} \mathrm{Hg}$ was 6.3 (2.9 to 14.6) compared with women with a diastolic pressure less than $64 \mathrm{~mm} \mathrm{Hg}$. Additional adjustment for prepregnancy body mass index did not influence these associations. Overweight and obese women had a higher risk of pre-eclampsia than women of normal weight and, similarly, the risk for pre-eclampsia increased with increasing waist circumference. Maternal height showed no association with pre-eclampsia.

Positive associations were found between prepregnancy serum levels of triglycerides, total cholesterol, and low density lipoprotein cholesterol and risk of preeclampsia (table 4). The risk increased with increasing levels; displaying a weak increase within the clinically normal range of these lipids, and showing stronger associations above the normal range. After additional adjustment for body mass index, these associations were only slightly attenuated (data not shown). Unfavourable 
levels of high density lipoprotein cholesterol and glucose were also associated with an increased risk of preeclampsia, but these associations were not as robust.

In a separate analysis the association between cardiovascular risk factors and risk of pre-eclampsia was investigated in nulliparous women (table 5). The results were similar to the overall results but showed slightly stronger associations for triglycerides. In additional analyses cases of pre-eclampsia were restricted to women with preterm delivery (to indicate early onset disease) and with term delivery (to indicate late onset). No apparent differences were found for early onset and late onset disease (table 6).

\section{DISCUSSION}

Unfavourable cardiovascular risk factors assessed before pregnancy are strong predictors of pre-eclampsia. Prepregnancy systolic and diastolic blood pressure showed linear associations with risk for pre-eclampsia, and the positive associations with levels of serum lipids (cholesterol, low density lipoprotein cholesterol, and triglycerides) were associated with particularly high risk among women with levels above the clinically normal range.

Other studies have assessed cardiovascular risk factors measured in ongoing pregnancies, ${ }^{81415}$ and some have reported associations between pre-eclampsia and prepregnancy obesity, chronic hypertension, or

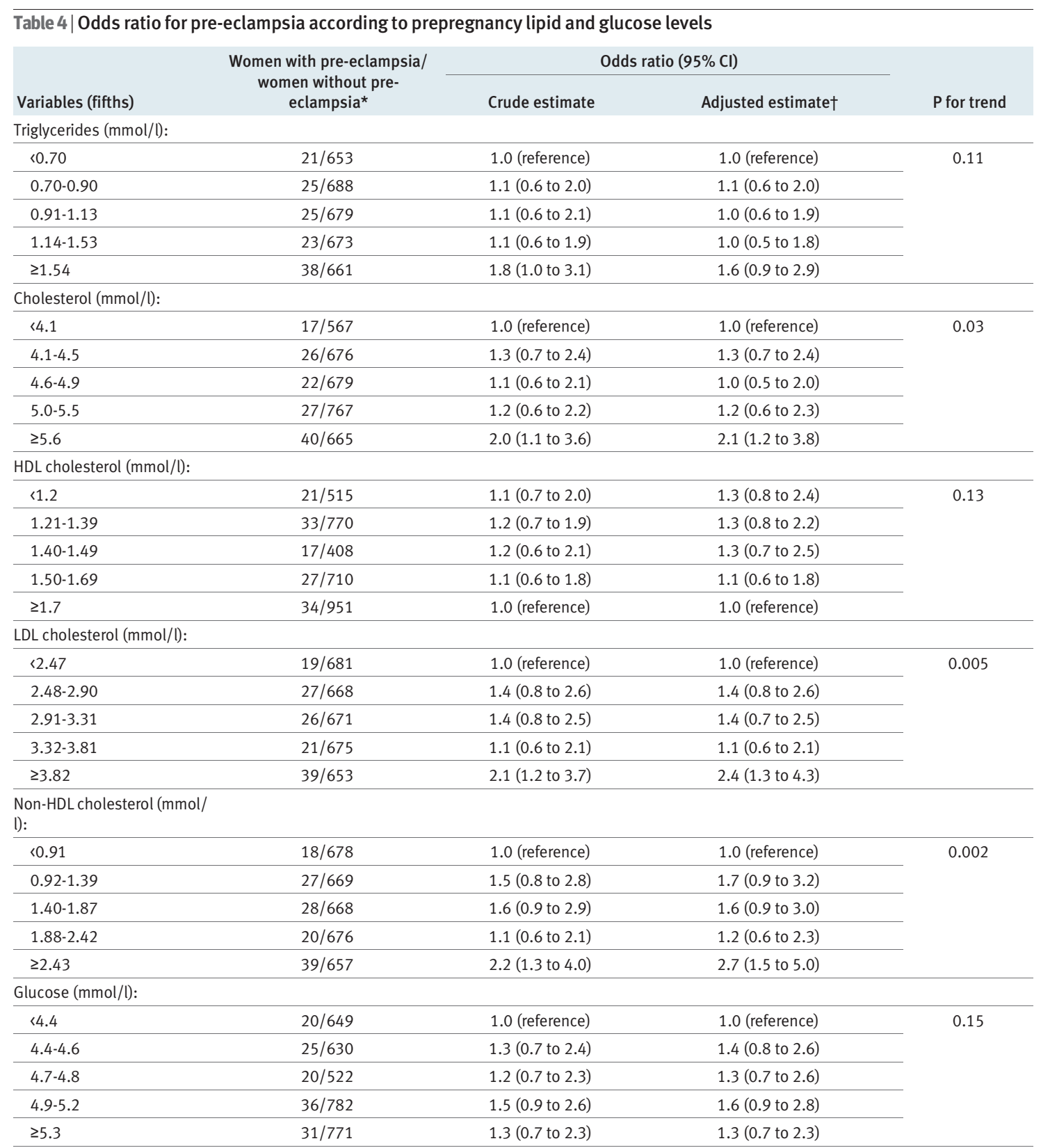

$\mathrm{HDL}=$ high density lipoprotein; LDL=low density lipoprotein.

*Some variation in number of women without pre-eclampsia owing to missing data, and data are missing on lipid and glucose levels in one woman with pre-eclampsia.

†Adjusted for maternal age at birth, duration between the baseline study and index delivery, education, parity, previous pre-eclampsia, smoking, receiving social security benefits, and time since last meal. 
hypercholesterolaemia. ${ }^{1617}$ No previous study has, however, prospectively examined the association of standardised measurements of blood pressure and lipid concentrations before pregnancy and risk of preeclampsia.

The prospective design and population base of this study make bias an unlikely explanation for the results. A limitation of this study, however, could be sampling blood in the non-fasting state. It has been shown that triglyceride concentrations are sensitive to recent food intake, but cholesterol levels seem to be less influenced. ${ }^{18}$ We tried to overcome this problem in the analyses of lipids by adjusting for time since last meal; this did not, however, alter the results, suggesting that non-fasting blood sampling may not cause a systematic bias. Our observed findings are likely to have been conservatively estimated, however, because nondifferential measurement error will have occurred that typically attenuates associations.

Pre-eclampsia can potentially be misclassified, and we cannot exclude this possibility in our study. If women with high blood pressure before pregnancy are, at a given level of blood pressure and proteinuria, more likely to have a diagnosis of pre-eclampsia during pregnancy this would generate a bias that would strengthen the association between prepregnancy blood pressure and pre-eclampsia. This could plausibly happen if surveillance for pre-eclampsia was greater among women with high blood pressure before pregnancy. This would not generally be known, however, and only six women had blood pressure consistent with hypertension before pregnancy. Therefore we feel that this potential source of bias is not likely to substantially influence our results.

\section{Family history}

The association between cardiovascular disease and diabetes in a first degree relative that we observed is in agreement with others. ${ }^{19-21}$ Unlike other studies, ${ }^{1920}$ we found no association with family history of cerebrovascular disease.

\section{Smoking}

Several studies have indicated that the risk of preeclampsia is lower in women who smoke than in women who do not smoke, but it is not fully understood how smoking may reduce the risk. ${ }^{22}$ Exposure to nicotine, carbon monoxide, stimulation of nitric oxide production, lowering of antiangiogenic factors, or a decreased immune response have been advanced as possible explanations for this observation. ${ }^{22-24}$ Women who smoke and develop pre-eclampsia seem to have a poorer outcome than women with preeclampsia who do not smoke. ${ }^{25}$ This may indicate a synergy between smoking and pre-eclampsia or, alternatively, that smoking may mask the symptoms of preeclampsia.

\section{Oral contraceptive use}

The negative association that we found with use of oral contraceptives at baseline is difficult to explain. Contrary to our results, another study reported an increased risk of pre-eclampsia and a reduced risk of gestational hypertension among women who used oral

\begin{tabular}{|c|c|c|c|c|}
\hline \multirow[b]{2}{*}{ Variables (fifths) } & \multirow{2}{*}{$\begin{array}{l}\text { Women with pre-eclampsia/ } \\
\text { women without pre- } \\
\text { eclampsia }\end{array}$} & \multicolumn{2}{|c|}{ Odds ratio $(95 \% \mathrm{Cl})$} & \multirow[b]{2}{*}{$P$ for trend } \\
\hline & & Crude estimate & Adjusted estimate* & \\
\hline \multicolumn{5}{|c|}{$\begin{array}{l}\text { Systolic blood pressure (mm } \\
\mathrm{Hg}) \text { : }\end{array}$} \\
\hline$\ll 111$ & $3 / 221$ & 1.0 (reference) & 1.0 (reference) & \multirow[t]{5}{*}{$<0.001$} \\
\hline $111-116$ & $8 / 258$ & $2.3(0.6$ to 8.7$)$ & $2.1(0.5$ to 8.1$)$ & \\
\hline $117-121$ & $16 / 244$ & $4.8(1.4$ to 16.8$)$ & $5.1(1.5$ to 17.8$)$ & \\
\hline $122-129$ & $23 / 327$ & $5.2(1.5$ to 17.4$)$ & $4.7(1.4$ to 15.9$)$ & \\
\hline$\geq 130$ & $35 / 353$ & $7.3(2.2$ to 24.0$)$ & 7.1 (2.2 to 23.5$)$ & \\
\hline \multicolumn{5}{|c|}{ Triglycerides (mmol/l)†: } \\
\hline$<0.70$ & $10 / 252$ & 1.0 (reference) & 1.0 (reference) & \multirow[t]{5}{*}{0.04} \\
\hline $0.70-0.90$ & $18 / 279$ & $1.6(0.7$ to 3.6$)$ & $1.6(0.7$ to 3.5$)$ & \\
\hline $0.91-1.13$ & $18 / 313$ & $1.5(0.7$ to 3.2$)$ & $1.4(0.6$ to 3.1$)$ & \\
\hline $1.14-1.53$ & $15 / 304$ & 1.3 (0.6 to 2.8$)$ & $1.2(0.5$ to 2.7$)$ & \\
\hline$\geq 1.54$ & $23 / 251$ & $2.3(1.1$ to 5.0$)$ & 2.3 (1.0 to 4.9$)$ & \\
\hline \multicolumn{5}{|c|}{ Cholesterol (mmol/l)†: } \\
\hline$<4.1$ & $11 / 252$ & 1.0 (reference) & 1.0 (reference) & \multirow[t]{5}{*}{0.07} \\
\hline 4.1-4.5 & $19 / 290$ & 1.5 (0.7 to 3.2$)$ & $1.4(0.7$ to 3.1$)$ & \\
\hline 4.6-4.9 & $15 / 299$ & $1.2(0.5$ to 2.6$)$ & 1.1 (0.5 to 2.5$)$ & \\
\hline $5.0-5.5$ & $15 / 318$ & $1.1(0.5$ to 2.4$)$ & 1.1 (0.5 to 2.5$)$ & \\
\hline$\geq 5.6$ & $24 / 240$ & $2.3(1.1$ to 4.8$)$ & 2.3 (1.1 to 4.8$)$ & \\
\hline
\end{tabular}

*Adjusted for maternal age at birth, duration between baseline study and index delivery, education, smoking, time since last meal, and receiving social security benefits.

†Additional adjustment for time since last meal. 
Table 6 | Odds ratio for preterm pre-eclampsia and for term pre-eclampsia according to prepregnancy level of systolic blood pressure, triglycerides, and cholesterol

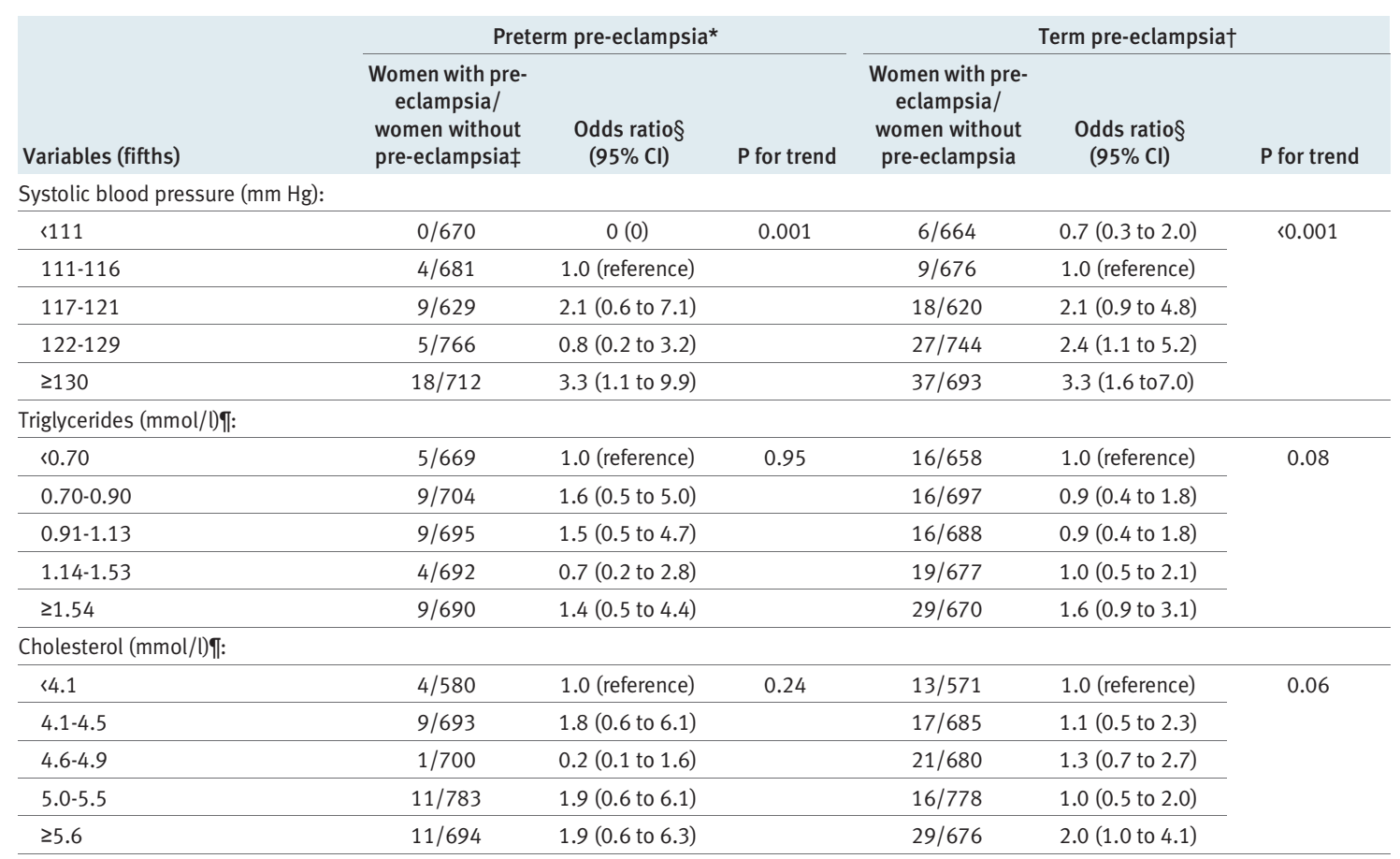

*Pre-eclampsia and delivery $\leq 36$ weeks' gestation.

†Pre-eclampsia and delivery at $\geq 37$ weeks' gestation.

$\ddagger$ Some variation in number of women without pre-eclampsia owing to missing data, and data were missing on triglycerides and cholesterol for one case of term pre-eclampsia.

§Adjusted for maternal age at birth, duration between baseline study and index delivery, education, smoking, time since last meal, previous preeclampsia, and receiving social security benefits.

IAdditional adjustment for time since last meal.

contraceptives. ${ }^{26}$ It is possible that screening for thromboembolic conditions and a family history of cardiovascular diseases among users of oral contraceptives could have resulted in the selection of women less prone to cardiovascular disease among baseline users of oral contraceptives in our study. However, we found no differences in cardiovascular risk factors between users, previous users, and never users of oral contraceptives at baseline. We also used time until pregnancy as a proxy variable for fertility, and examined whether time to pregnancy could have confounded the results. We found no association between this proxy for fertility and risk of pre-eclampsia. Since a long interval between pregnancies increases the risk of preeclampsia, ${ }^{27}$ we also restricted the analysis to nulliparous women, but the negative association with use of oral contraceptives at baseline persisted. The "immune maladaptation" theory of exposure by sperm and risk of pre-eclampsia suggests that barrier methods of contraception may increase the risk of pre-eclampsia and conversely that oral contraceptive use may decrease the risk. ${ }^{28}$ However, this theory has not been supported in recent studies. ${ }^{2729}$

Early and late onset pre-eclampsia

Several studies have suggested that early onset and late onset pre-eclampsia, often termed mild and severe preeclampsia, may be two different entities with different causes ${ }^{30-32}$ whereas others suggest that the risk profiles are similar for these groups. ${ }^{33}$ The results of this study support similarity, since the associations with cardiovascular risk factors showed similar patterns for early onset (pre-eclampsia and delivery at $\leq 36$ weeks) and late onset pre-eclampsia (pre-eclampsia and delivery at $\geq 37$ weeks). This finding must be interpreted with caution, however, as we have only indirect data on early and late onset pre-eclampsia and the number of cases with the combination of pre-eclampsia and preterm birth is small.

\section{Pre-eclampsia and cardiovascular disease}

Healthy pregnancies are typically characterised by insulin resistance compared with the non-pregnant state, including up-regulation of maternal carbohydrate and lipid metabolism. ${ }^{4-730}$ These adaptive responses to pregnancy meet demands of the rapidly developing fetus, ${ }^{47}$ and in pre-eclamptic pregnancies these metabolic up-regulations seem to be exaggerated compared with uncomplicated pregnancies. ${ }^{4730}$ Therefore the excessive metabolic changes of preeclamptic pregnancies may be regarded as a stress test for maternal cardiovascular function. ${ }^{34}$ Several studies have linked pre-eclampsia with higher risk of future cardiovascular disease of the mother, ${ }^{1-3}$ suggesting that pre-eclampsia and cardiovascular diseases may share common pathophysiological 


\section{WHAT IS ALREADY KNOWN ON THIS TOPIC}

Women with previous pre-eclampsia are at increased risk of cardiovascular diseases

Women with pre-eclampsia have unfavourable metabolic profiles in pregnancy

\section{WHAT THIS STUDY ADDS}

Cardiovascular risk factors that are present years before pregnancy are associated with a risk of pre-eclampsia
5 Sattar N, Bendomir A, Berry C, Shepherd I, Greer IA, Packard CI. Lipoprotein subfraction concentrations in preeclampsia: pathogenic parallels to atherosclerosis. Obstet Gynecol 1997;89:403-8.

6 Redman CW, Sacks GP, Sargent IL. Preeclampsia: an excessive maternal inflammatory response to pregnancy. Am J Obstet Gynecol 1999;180:499-506.

7 Sattar N, Greer IA, Louden J, Lindsay G, McConnell M, Shepherd J, et al. Lipoprotein subfraction changes in normal pregnancy. I Clin Endocrinol Metab 1997;82:2483-91.

8 Ray JG, Diamond P, Singh G, Bell CM. Brief overview of maternal triglycerides as a risk factor for preeclampsia. Br J Obstet Gynaecol 2006;113:379-86.

9 Holmen J, Midthjell K, Kruger $\varnothing$, Langhammer A, Lingaas Holmen T, Bratberg GH, et al. The Nord-Trøndelag health study 1995-97 (HUNT 2). Norsk Epidemiol 2003;13:19-32.

mechanisms.$^{45}$ The pathogenesis of pre-eclampsia is uncertain, but predisposition to endothelial dysfunction is thought to play a crucial part. ${ }^{463035}$ Risk factors for pre-eclampsia such as chronic hypertension, renal disease, and diabetes are all conditions where endothelial dysfunction is a common feature. ${ }^{430}$ Furthermore, unfavourable lipid levels are associated with endothelial dysfunction and may precede the development of atheromatous disease. ${ }^{36}$ Studies have also shown acute atherosis in vessels of the placenta bed in pre-eclamptic women. ${ }^{37}$ Finally, it would be possible to test the causal effect of some of these risk factorssuch as increased low density lipoprotein cholesterol or triglyceride levels - on risk of pre-eclampsia by relating genotypes associated with different average levels of these factors to risk of pre-eclampsia and utilising the principle of mendelian randomisation. ${ }^{38}$

In conclusion, we found that cardiovascular risk factors that were present years before pregnancy are associated with a risk of pre-eclampsia. This finding suggests that unfavourable cardiovascular and metabolic profiles may represent primary causes of preeclampsia and that these factors predispose both to pre-eclampsia and to subsequent cardiovascular disease. This does not, however, rule out the possibility that the pre-eclamptic process in itself may also contribute to cardiovascular risk.

We thank the Nord-Trøndelag health study and the Norway's medical birth registry for providing the data and the women who participated in this study.

Contributors: PRR had the original idea for the study. EBM analysed the data and wrote the paper together with PRR. LV, GDS, and KÅS participated in the interpretation of results and the writing of the paper. TIL participated in the statistical analyses and interpretation of the results. PRR has access to the original data and is guarantor.

Funding: This study was supported by a grant from the Norwegian Medical Research Council. The Nord-Trøndelag health study is a collaboration between the Norwegian University of Science and Technology, the Norwegian Institute of Public Health, and Nord-Trøndelag County Council.

Competing interests: None declared.

Ethical approval: This study was approved by regional science ethics committees in Norway and the medical birth registry of Norway.

1 Irgens HU, Reisaeter L, Irgens LM, Lie RT. Long term mortality of mothers and fathers after pre-eclampsia: population based cohort study. BMJ 2001;323:1213-7.

2 Ray JG, Vermeulen MJ, Schull MI, Redelmeier DA. Cardiovascular health after maternal placental syndromes (CHAMPS): populationbased retrospective cohort study. Lancet 2005;366:1797-803.

3 Smith GC, Pell JP, Walsh D. Pregnancy complications and maternal risk of ischaemic heart disease: a retrospective cohort study of 129,290 births. Lancet 2001;357:2002-6.

4 Rodie VA, Freeman DJ, Sattar N, Greer IA. Preeclampsia and cardiovascular disease: metabolic syndrome of pregnancy? Atherosclerosis 2004;175:189-202.
10 Irgens LM. The medical birth registry of Norway. Epidemiolgical research and surveillance throughout 30 years. Acta Obstet Gyneco Scand 2000;79:435-9.

11 Report of the National High Blood Pressure Education Program Working Group on high blood pressure in pregnancy. Am J Obstet Gynecol 2000;183:S1-22.

12 Friedewald WT, Levy RI, Fredrickson DS. Estimation of the concentration of low-density lipoprotein cholesterol in plasma, without use of the preparative ultracentrifuge. Clin Chem 1972;18:499-502.

13 Packard CJ, Saito Y. Non-HDL cholesterol as a measure of atherosclerotic risk. J Atheroscler Thromb 2004;11:6-14.

14 Duckitt K, Harrington D. Risk factors for pre-eclampsia at antenatal booking: systematic review of controlled studies. BMJ 2005;330:565-72.

15 Wolf M, Sandler L, Munoz K, Hsu K, Ecker JL, Thadhani R. First trimester insulin resistance and subsequent preeclampsia. J Clin Endocrinol Metab 2002;87:1563-8.

16 Thadhani R, Stampfer MJ, Hunter DJ, Manson JE, Solomon CG, Curhan GC. High body mass index and hypercholesterolemia: risk of hypertensive disorders of pregnancy. Obstet Gynecol 1999:94:543-50.

17 O'Brien TE, Ray JG, Chan WS. Maternal body mass index and the risk of preeclampsia: a systematic overview. Epidemiology 2003;14:368-74.

18 Craig SR, Amin RV, Russell DW, Paradise NF. Blood cholesterol screening influence of fasting state on cholesterol results and management decisions. J Gen Intern Med 2000;15:395-9.

19 Ness RB, Markovic N, Bass D, Harger G, Roberts JM. Family history of hypertension, heart disease, and stroke among women who develop hypertension in pregnancy. Obstet Gynecol 2003;102:1366-71.

20 Wilson BJ, Watson MS, Prescott GJ, Sunderland S, Campbell DM, Hannaford P, et al. Hypertensive diseases of pregnancy and risk of hypertension and stroke in later life: results from cohort study. BMJ 2003;326:845.

21 Qiu C, Williams MA, Leisenring WM, Sorensen TK, Frederick IO, Dempsey JC, et al. Family history of hypertension and type 2 diabetes in relation to preeclampsia risk. Hypertension 2003;41:408-13.

22 Conde-Agudelo A, Althabe F, Belizan JM, Kafury-Goeta AC. Cigarette smoking during pregnancy and risk of preeclampsia: a systematic review. Am J Obstet Gynecol 1999;181:1026-35.

23 Beste LA, England LJ, Schisterman EF, Qian C, Yu KF, Levine RJ. Pregnancy outcomes in smokers who develop pre-eclampsia. Paediatr Perinat Epidemiol 2005;19:12-8.

24 Bainbridge SA, Sidle EH, Smith GN. Direct placental effects of cigarette smoke protect women from pre-eclampsia: the specific roles of carbon monoxide and antioxidant systems in the placenta. Med Hypotheses 2005;64:17-27.

25 Salafia C, Shiverick K. Cigarette smoking and pregnancy II: vascular effects. Placenta 1999;20:273-9.

26 Thadhani R, Stampfer MJ, Chasan-Taber L, Willett WC, Curhan GC. A prospective study of pregravid oral contraceptive use and risk of hypertensive disorders of pregnancy. Contraception 1999;60:145-50

27 Skjaerven R, Wilcox AJ, Lie RT. The interval between pregnancies and the risk of preeclampsia. N Engl/ Med 2002;346:33-8.

28 Klonoff-Cohen HS, Savitz DA, Cefalo RC, McCann MF. An epidemiologic study of contraception and preeclampsia. JAMA 1989;262:3143-7.

29 Ness RB, Markovic N, Harger G, Day R. Barrier methods, length of preconception intercourse, and preeclampsia. Hypertens Pregnancy 2004; $23: 227-35$.

30 Sibai B, Dekker G, Kupferminc M. Preeclampsia. Lancet 2005;365:785-99.

31 Clausen T, Djurovic S, Henriksen T. Dyslipidemia in early second trimester is mainly a feature of women with early onset preeclampsia. Br J Obstet Gynaecol 2001;108:1081-7.

32 Vatten LJ, Skjaerven R. Is pre-eclampsia more than one disease? Br J Obstet Gynaecol 2004;111:298-302. 
33 Bodnar LM, Catov JM, Klebanoff MA, Ness RB, Roberts JM. Prepregnancy body mass index and the occurrence of severe hypertensive disorders of pregnancy. Epidemiology 2007;18:234-9.

34 Sattar N, Greer IA. Pregnancy complications and maternal cardiovascular risk: opportunities for intervention and screening? BMJ 2002;325:157-60.

35 Ness RB, Sibai BM. Shared and disparate components of the pathophysiologies of fetal growth restriction and preeclampsia. Am J Obstet Gynecol 2006;195:40-9.
36 Goode GK, Miller JP, Heagerty HM. Hyperlipidaemia, hypertension and coronary heart disease. Lancet 1995;345:362-4.

37 Pijnenborg R, Anthony J, Davey DA, Rees A, Tiltman A, Vercruysse L, et al. Placental bed spiral arteries in the hypertensive disorders of pregnancy. BrJ Obstet Gynaecol 1991;98:648-55.

38 Smith GD, Ebrahim S. Mendelian randomization: prospects, potentials, and limitations. Int J Epidemiol 2004;33:30-42.

Accepted: 9 October 2007 